\title{
AVALIAC̃̃̃ E REMOÇ̃̃o de COBRE EM AGUARDENTES DE CANA PELA UTILIZAÇÃO DOS ALUMINOSSILICATOS: ZEÓLITA E BENTONITA ${ }^{1}$
}

\author{
Evaluation and removal of sugar cane brandy using aluminossilicates: zeolite and bentonite ${ }^{1}$
}

\author{
Fabiane de Oliveira Cantã $0^{2}$, Walclée de Carvalho Melo ${ }^{3}$, Maria das Graças Cardoso ${ }^{3}$, \\ Jeancarlo Pereira dos Anjos ${ }^{4}$, Luiz Carlos Alves de Oliveira ${ }^{3}$
}

\begin{abstract}
RESUMO
A cachaça, bebida genuinamente nacional, é um produto de grande aceitação nos mercados interno e externo. Durante o processo de produção há alguns pontos críticos, ocorrendo a formação de contaminantes que podem afetar a qualidade da bebida, sendo necessário o conhecimento de sua composição química. Com este trabalho, objetivou-se comparar o comportamento do cobre, quando presente em solução alcoólica $40 \%$ e uma aguardente comercial (utilizando sulfato de cobre pentaidratado como fonte desse mesmo metal), além de avaliar a remoção de cobre na bebida, utilizando dois aluminossilicatos (zeólita e bentonita) comumente empregados na adsorção de metais. A zeólita e bentonita adsorveram mais cobre quando estiveram presentes em solução alcoólica do que em aguardente. Esses resultados sugerem que o cobre em aguardente deva estar ligado a moléculas volumosas, dificultando sua entrada nos pequenos poros da argila bentonita e da zeólita ZSM-5. Quando os aluminossilicatos estiveram presentes na aguardente impregnada com cobre em alambique, a bentonita foi mais eficiente na remoção do cobre do que a zeólita; no entanto a zeólita é mais recomendada na remoção do cobre, pois a redução das concentrações dos componentes secundários foi menor, não descaracterizando a bebida.
\end{abstract}

Termos para indexação: Aguardente, cobre, adsorção.

\begin{abstract}
The "cachaça", a genuinely national drink, is a product of great acceptance in the domestic and international markets. Therefore, we need to know its chemical composition, as in the production process a few critical points due to the presence of contaminants that can affect the quality of the drink. This work is aimed to compare the behaviour of copper, when present in a $40 \%$ alcohol solution and a "cachaça" trade (using copper sulfate pentahydrate as a source of the same metal), in addition to evaluating the removal of copper in the spirit, using two aluminosilikate (zeolite and bentonite) commonly employed in the adsorption of metals. The zeolite and bentonite adsorbed more copper when were present in alcoholic solution than in spirits. These results suggest that copper in spirits should be linked to large molecules, hampering its entry in the small pores of the bentonite clay and zeolite ZSM-5. When the aluminosilikate were present in spirit impregnated with copper still in the bentonite was more efficient in the removal of copper than zeolite, although the zeolite is recommended in the removal of copper in the spirit, because the reduction of concentrations of the components side was lower, not losing its peculiar feature.
\end{abstract}

Index terms: Sugar-cane brandy, copper, adsorption.

(Recebido em 8 de outubro de 2008 e aprovado em 5 de maio 2009)

\section{INTRODUÇÃO}

A aguardente de cana, bebida genuinamente nacional, é produzida praticamente em todo o Brasil. Cardoso (2006) cita que entre as bebidas destiladas, é a mais consumida no país. De acordo com Drinks International (1994), já foi o destilado mais consumido no mundo. Dados oficiais indicam uma produção de 1,6 bilhão de litros anuais existindo atualmente mais de 5 mil marcas registradas, com cerca de 30 mil produtores em todo o país. As exportações representam apenas $1 \%$ da produção total, sendo os principais países importadores: Alemanha, Portugal e Estados Unidos (Lima et al., 2006).
A cachaça é definida com sendo uma denominação típica e exclusiva para aguardente de cana produzida no Brasil, com graduação alcoólica de 38-48\% em volume, a $20^{\circ} \mathrm{C}$, com características sensoriais peculiares (Brasil, 2005b). A cachaça artesanal é produzida em alambique de cobre sendo muito apreciada por consumidores de todas as classes sociais. Acredita-se que esse metal confere melhor qualidade ao produto, quando comparado aos alambiques confeccionados com outros materiais, como aço inox; porém, podem contaminar o produto quando o manejo (principalmente a higiene) da produção é inadequado (Nascimento et al., 1998; Cardoso, 2006; Lima et al., 2009). Durante o processo de destilação, forma-se o

${ }^{1}$ Extraído da Dissertação de Mestrado apresentada pela primeira autora à Universidade Federal de Lavras, Lavras, MG

'Universidade Federal de Lavras/UFLA - Cx. P. 3037 - 37200-000 - Lavras, MG - fabiane_cantao@yahoo.com.br

${ }^{3}$ Universidade Federal de Lavras/UFLA - Departamento de Química/DQI - Lavras, MG

${ }^{4}$ Universidade Federal de Lavras/UFLA - Lavras, MG 
"azinhavre" $\left[\mathrm{CuCO}_{3} \mathrm{Cu}(\mathrm{OH})_{2}\right]$, nas paredes internas dos alambiques de cobre. Esse composto é dissolvido pelos vapores alcoólicos ácidos, durante o processo de destilação da bebida, contaminando o destilado. A legislação brasileira limita o teor de cobre em bebidas destiladas em $5 \mathrm{mg} / \mathrm{L}$, entretanto, a legislação de outros países não tolera mais que $2 \mathrm{mg} / \mathrm{L}$ de cobre em destilados alcoólicos (Nascimento et al., 1999; Lima et al., 2006).

Cardoso (2001) recomenda fazer uma primeira destilação com suco de limão, à base de 5 litros de suco para cada 100 litros de água. EsSa solução removerá o azinhavre do alambique, principalmente Aquele existente no interior da serpentina de condensação dos vapores alcoólicos. Muitos produtores não atentam para essa medida de prevenção e acabam por utilizar substâncias adsorventes, como resinas de troca iônica ou carvão ativado, para a remoção do excesso do metal da bebida, porém outros compostos secundários podem ser removidos da bebida (Lima et al., 2006).

Neste contexto, inúmeras pesquisas vêm sendo realizadas com o objetivo de aprimorar tanto a qualidade da matéria-prima, variedades de cana-de-açúcar, quanto os cuidados durante o processo de fermentação e destilação, bem como o controle de compostos contaminantes. (Maia et al., 1991; Mutton \& Mutton, 1992; Vargas \& Glória, 1995., Cleto et al., 2009, Leite, et al., 2008, Costa et al., 2008). Novos materiais vêm sendo utilizados na tentativa de retirar o excesso do metal da bebida, nos quais os aluminossilicatos mostram-se promissores devido ao fato desses apresentarem uma estrutura que permite a troca iônica entre o metal presente nesses com o cobre presente na bebida.

Com este trabalho, objetivou-se comparar o comportamento do cobre, quando presente em solução alcoólica $40 \%$ e uma aguardente comercial (utilizando sulfato de cobre pentaidratado como fonte desse mesmo metal), além de avaliar a remoção de cobre na bebida, utilizando dois aluminossilicatos (zeólita e bentonita) comumente empregados na adsorção de metais.

\section{Aluminossilicatos}

A sílica ocorre na natureza com a fórmula empírica aproximadamente igual a $\left(\mathrm{SiO}_{2}\right)$. A substituição parcial de átomos de silício por alumínio dá origem ao grupo dos aluminossilicatos. Os principais componentes desse grupo são as argilas e as zeólitas (Cotton \& Wilkinson, 1999; Aguiar et al., 2002).

As zeólitas podem ser definidas como aluminossilicatos cristalinos com uma estrutura tridimensional composta por um conjunto de cavidades ocupadas por grandes íons e moléculas de água, ambos com considerável liberdade de movimento, permitindo a troca iônica e uma hidratação reversível. A capacidade de adsorção das zeólitas é resultante da sua alta área superficial e de sua carga líquida negativa nos canais de sua estrutura, que atraem cátions, tais como metais pesados. Por essas razões, diferentes zeólitas têm sido estudadas como adsorventes de contaminantes metálicos (Penã et al., 2000; Jimenez et al., 2004; Pergher et al., 2005).

O termo bentonita, foi pela primeira vez aplicado a um tipo de argila plástica descoberta em Fort Benton, Wyoming- EUA. O termo bentonita é usado para designar uma argila com alto teor de montmorilonita. A bentonita pode ser cálcica, sódica, policatiônica, etc. Quando sódica apresenta uma característica física muito particular de expandir várias vezes o seu volume e quando em contato com a água, forma géis tixotrópicos (Silva \& Ferreira, 2008).

Este trabalho teve como objetivo comparar o comportamento do cobre, quando presente em solução alcoólica $40 \%$ e uma aguardente comercial (utilizando sulfato de cobre pentaidratado como fonte deste mesmo metal), além de avaliar a remoção de cobre na aguardente de cana, utilizando dois aluminossilicatos (zeólita e bentonita) comumente empregados na adsorção de metais.

\section{MATERIAL E METODOS}

Foram utilizadas 10 amostras de aguardente provenientes das regiões Sul, Norte e Zona da Mata do estado de Minas Gerais. Essas foram levadas ao Laboratório de Análises Físico-Químicas de Aguardentes (LAFQA - DQI - Universidade Federal de Lavras), Lavras, MG, para realização das análises físico-químicas e testes de adsorção.

\section{Adsorção de cobre em etanol e aguardente comercial utilizando sulfato de cobre como fonte do metal}

Para observar o comportamento do cobre em etanol - 40\% (simulando uma aguardente industrial) e em aguardente (cachaça artesanal), foram realizados testes de adsorção com dois materiais comumente empregados em adsorção de metais (zeólita ZSM-5 e bentonita).

Para a análise de adsorção de cobre foram utilizadas as seguintes soluções: sulfato de cobre pentidratado em etanol e sulfato de cobre pentidratado em aguardente comercial.

No ensaio de adsorção, foi empregado o sulfato de cobre nas concentrações $25,50,100,250$ e $500 \mathrm{mg} / \mathrm{L}$ e os aluminossilicatos: zeólita e bentonita. Utilizaram-se $10 \mathrm{~mL}$ 
de cada solução e $5 \mathrm{mg}$ de cada aluminossilicato, sendo esses deixados em contato por 24 horas, sob agitação constante. Logo em seguida, o material foi filtrado, diluído e posteriormente submetido à leitura em um espectrofotômetro de absorção atômica em espectrômetro Varian AA - 175, com gás combustível acetileno e ar como suporte, lâmpada de cátodo oco, fenda $0,2 \mathrm{~mm}$, comprimento de onda 324,8 nm, voltagem de $460 \mathrm{v}$ e amperagem de $3 \mathrm{~A}$.

Os valores de cobre foram obtidos por meio de comparação das leituras observadas nas amostras de aguardente, com valores referentes a uma curva de calibração construída previamente. A quantidade de cobre foi expressa em miligrama de cobre por litro da amostra. Pelos valores de cobre encontrados, foi possível calcular o $\mathrm{q}_{\mathrm{eq}}$ (quantidade de cobre adsorvida), pela seguinte equação: $\mathrm{q}_{\mathrm{eq}}=\left(C_{i}-C_{e}\right) \frac{V(L)}{m(g)}$, em que $C_{i}$ é a concentração inicial de cobre antes da adsorção, $C_{e}$ é a concentração de cobre após a adsorção, sendo a concentração de equilíbrio, $V$ é o volume de solução utilizado, em litros, e $m$ é a massa, em gramas, de aluminossilicato utilizado.

Com esses resultados foi possível construir as isotermas, que permitem visualizar todo o processo de adsorção.

\section{Adsorção de cobre e avaliação dos congêneres aldeídos, ésteres e álcoois superiores após adsorção}

Para simulação de níveis elevados de cobre, fez-se um blend (mistura) de 10 amostras de aguardentes, as quais foram armazenadas em alambique de cobre e estas foram enriquecidas com cobre até $6,63 \mathrm{mg} / \mathrm{L}$ do metal. Para um novo ensaio de adsorção empregou-se $0,2 \mathrm{~g}$ dos aluminossilicatos (zeólita e bentonita) em $400 \mathrm{~mL}$ de aguardente, separadamente. Logo a seguir, esse material foi deixado em contato por 24 horas, sob agitação constante e posteriormente filtrado. Como método de comparação foi utilizada uma testemunha, sendo que essa foi uma amostra que não passou pelo processo de adsorção. Uma fração de cada amostra foi reservada para a quantificação de cobre (sendo esse submetido à leitura em um espectrofotômetro de absorção atômica) e o restante foi submetido à destilação para a dosagem de aldeídos, ésteres e álcoois superiores.

Os valores de cobre foram obtidos da mesma forma descrita anteriormente.

\section{Avaliação da qualidade das aguardentes}

Foram feitas determinações seguindo as especificações estabelecidas pelo Ministério da Agricultura, Pecuária e Abastecimento (MAPA) (Brasil, 2005b), como seguem:
- aldeídos: são compostos muito voláteis, de odor penetrante, que afetam o aroma das bebidas alcoólicas (Cardoso, 2006). Foram dosados por meio de métodos iodométricos, sendo titulado o $\mathrm{SO}_{2}$ produzido durante a sequência de reações do processo analítico. A quantidade de aldeídos presentes nas amostras foi expressa em gramas de aldeído acético por $100 \mathrm{~mL}$ da amostra ou para $100 \mathrm{~mL}$ de álcool anidro.

- ésteres: apresentam odor agradável de frutas e são considerados compostos importantes de aroma nas bebidas alcoólicas (Lehtonem \& Jounela-Eriksson, 1983; Cardoso, 2006). Foram determinados por meio da titulação dos ácidos carboxílicos obtidos por transesterificação dos ésteres presentes nas amostras de aguardente. A quantidade total dos ésteres foi expressa em miligramas de acetato de etila para $100 \mathrm{~mL}$ de álcool anidro.

- álcoois superiores: conhecidos como óleo fúsel, geralmente apresentam um odor característico de flores, e juntamente com os ésteres são responsáveis pelo flavour da aguardente. Os principais álcoois superiores encontrados na bebida são os álcoois isoamílico (2metilbutanol-1), amílico (pentanol), isobutílico (2metilpropanol-1) e propílico (propanol) (Vilela et al., 2007). A quantidade total foi determinada por meio de medidas espectrofotométricas efetuadas na região visível do espectro $(540 \mathrm{~nm})$. Para efetuar essa quantificação, foram comparados os valores de absorbância referentes às amostras com uma curva de calibração previamente construída, utilizando-se uma mistura de álcoois superiores solubilizados em solvente água/etanol. A quantidade total de álcoois superiores foi expressa em miligrama por $100 \mathrm{~mL}$ de álcool anidro.

- cobre: foi determinado em espectrofotômetro de absorção atômica.

\section{RESULTADOS E DISCUSSÃO}

\section{Adsorção do cobre em etanol e aguardente}

Os resultados da adsorção de cobre pelos aluminossilicatos (bentonita e zeólita ZSM -5) mostram-se pelas isotermas de adsorção (Figura 1-4) nas soluções alcoólicas $40 \%$ e aguardente.

Pelas isotermas de adsorção de cobre, verificou-se que tanto a zeólita quanto a bentonita adsorveram cobre de modo semelhante. Por meio delas, pôde-se verificar também que tanto a zeólita ZSM-5 quanto a bentonita adsorveram significativamente mais cobre em etanol, quando comparados ao cobre em aguardente. De acordo com as isotermas, a capacidade máxima de adsorção de 
cobre em etanol para a zeólita foi de, aproximadamente, $717 \mathrm{mg} \mathrm{Cu} \mathrm{Cu}^{2+} / \mathrm{g}_{\text {zeólita }}$ e para a aguardente foi de aproximadamente $50 \mathrm{mg} \mathrm{Cu}{ }^{2+} / g_{\text {zeólita }}$. A capacidade máxima de adsorção de cobre em etanol para a bentonita foi de aproximadamente $690 \mathrm{mg} \mathrm{Cu}^{2+} / \mathrm{g}_{\text {bentonita }}$ e para a aguardente foi de aproximadamente $90 \mathrm{mg} \mathrm{Cu} \mathrm{Cu}^{2+} \mathrm{g}_{\text {bentonita }}$. Com esses resultados infere-se que o cobre em aguardente de cana pode estar ligado a moléculas volumosas, como, por exemplo, álcoois superiores, dificultando sua entrada nos poros da argila (bentonita) e da zeólita (ZSM-5), havendo uma menor adsorção deste metal. Na Figura 5 há um esquema da adsorção de cobre nos poros dos aluminossilicatos.

\section{Avaliação dos congêneres aldeídos, álcoois superiores e ésteres após adsorção de cobre}

Os resultados da avaliação dos congêneres estão apresentam-se na Tabela 1 .

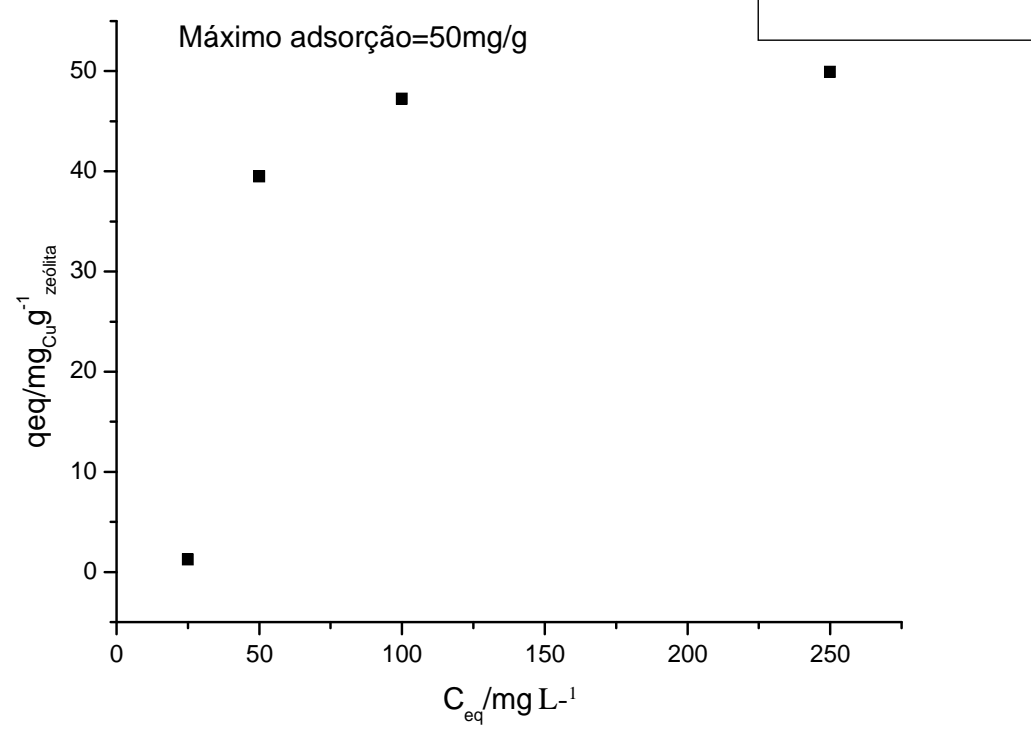

Figura 1 - Isoterma de adsorção de $\mathrm{Cu}^{2+}$ em zeólita/aguardente.

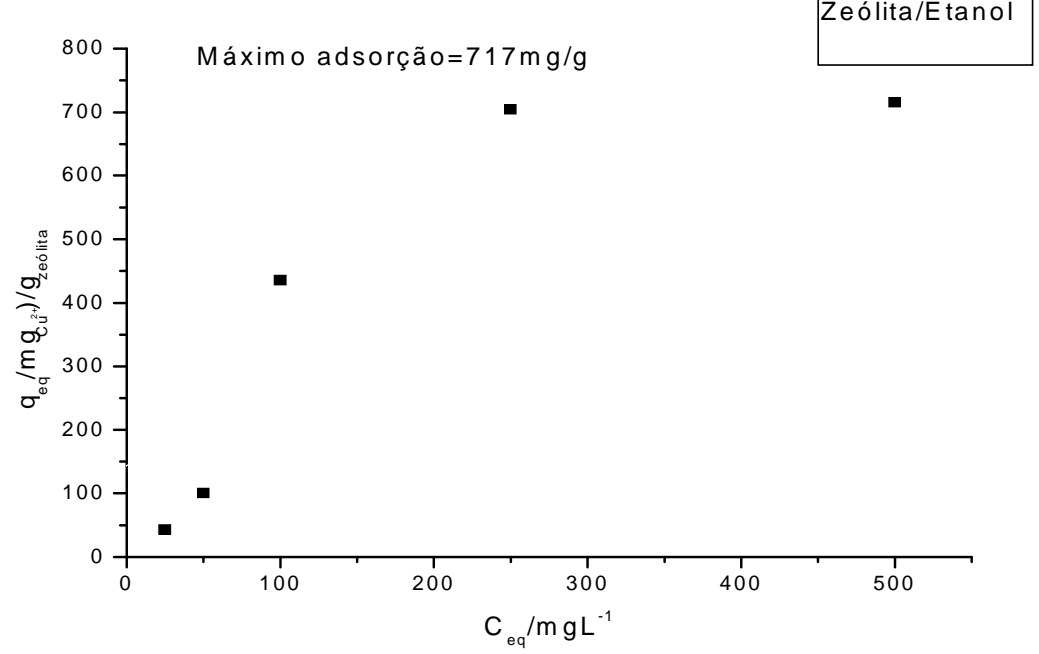

Figura 2 - Isoterma de adsorção de $\mathrm{Cu}^{2+}$ em zeólita/etanol. 


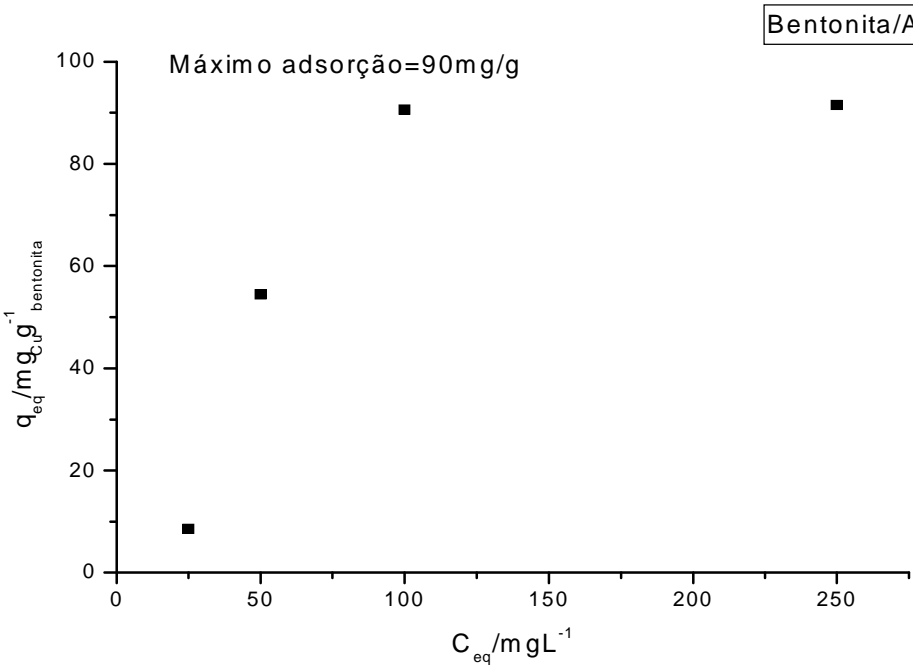

Figura 3 - Isoterma de adsorção de $\mathrm{Cu}^{2+}$ em bentonita/aguardente.

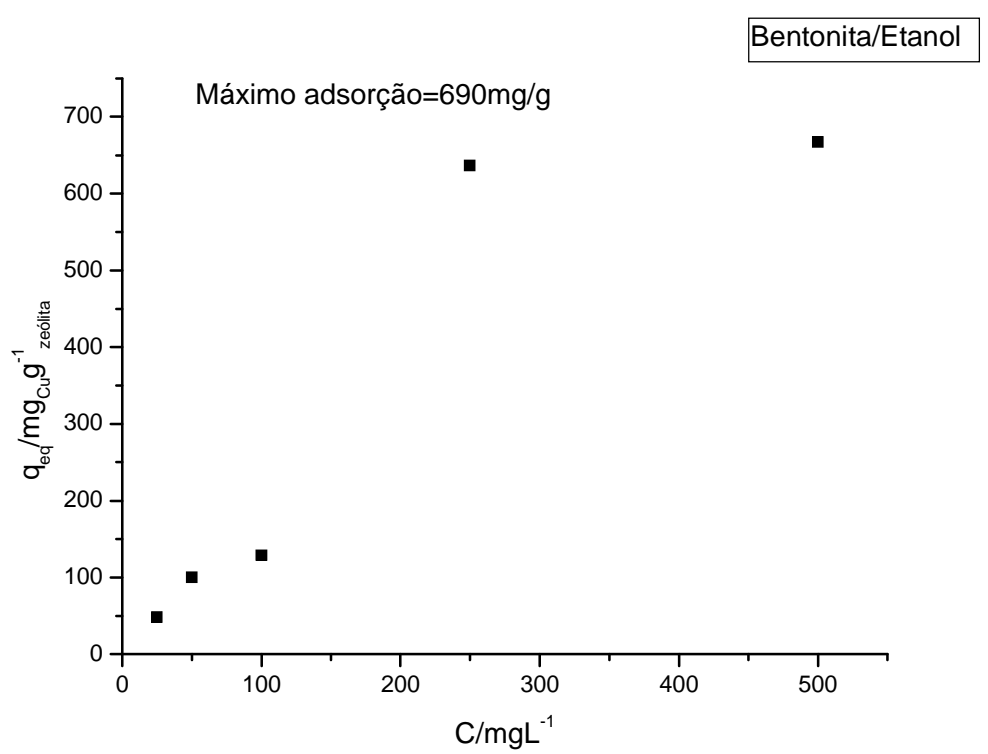

Figura 4 - Isoterma de adsorção de $\mathrm{Cu}^{2+}$ em bentonita/etanol.

Observa-se que a bentonita foi mais eficiente na remoção do cobre do que a zeólita. A redução foi de 29,4\% em relação à testemunha, o que foi suficiente para resultar em um valor abaixo do limite máximo permitido pela legislação. Já no caso da zeólita, a redução de 21,6\%, apesar de ter sido relevante, não foi suficiente para abaixar a concentração de cobre ao nível exigido. Pode-se observar ainda que a utilização desses materiais adsorventes alterou a concentração dos componentes que dão sabor e aroma à bebida (álcoois superiores, aldeídos e ésteres), depreciando a qualidade da bebida.
Apesar de apresentar uma maior eficiência na remoção do cobre, a bentonita promoveu maior redução na concentração de congêneres, quando comparada com a zeólita.

No caso dos álcoois superiores, a bentonita promoveu uma redução de 13,9\% em relação à testemunha, ao passo que a zeólita contribuiu com $21,6 \%$ para a redução destes. Quanto aos aldeídos, a bentonita e a zeólita promoveram reduções de $7,8 \%$ e $3,4 \%$, respectivamente; em relação aos ésteres, as reduções foram de 19,5\% para a bentonita e 7,8\% para a zeólita. 

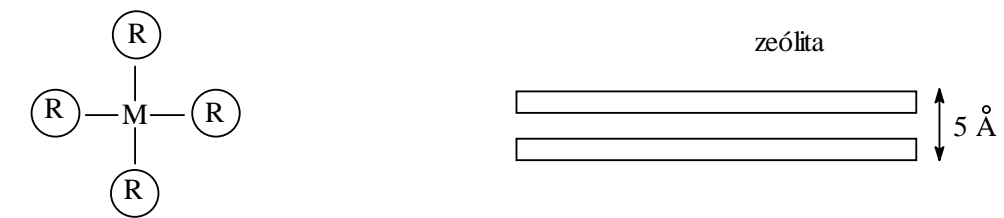

* $\mathrm{R}=$ álcoois superiores

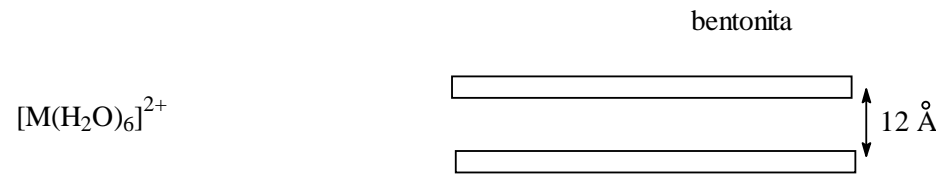

Figura 5 - Esquema da adsorção de $\mathrm{Cu}^{2+}$ em zeólita ZSM-5 e bentonita.

Tabela 1 - Concentração dos principais congêneres da aguardente, após adsorção de cobre, e variação porcentual em relação à testemunha.

\begin{tabular}{lcccccccc}
\hline Tratamento & $\begin{array}{c}\text { Cobre } \\
(\mathrm{mg} / \mathrm{L})\end{array}$ & $\begin{array}{c}\text { Var. } \\
(\%)\end{array}$ & $\begin{array}{c}\text { Alc. Sup. } \\
(\mathrm{mg} / 100 \mathrm{~mL} \\
\text { de a.a* })\end{array}$ & $\begin{array}{c}\text { Var. } \\
(\%)\end{array}$ & $\begin{array}{c}\text { Aldeídos } \\
(\mathrm{mg} / 100 \mathrm{~mL} \\
\left.\text { de a. } \mathrm{a}^{*}\right)\end{array}$ & $\begin{array}{c}\text { Var. } \\
(\%)\end{array}$ & $\begin{array}{c}\text { Ésteres } \\
(\mathrm{mg} / 100 \mathrm{~mL} \\
\text { de a.a*) }\end{array}$ & $\begin{array}{c}\text { Var. } \\
(\%)\end{array}$ \\
\hline Test.** & 6,63 & - & 226,54 & - & 16,96 & - & 62,25 & - \\
Bentonita & 4,68 & $-29,4$ & 195,03 & $-13,9$ & 15,63 & $-7,8$ & 50,09 & $-19,5$ \\
Zeolita & 5,20 & $-21,6$ & 203,54 & $-10,2$ & 16,38 & $-3,4$ & 57,38 & $-7,8$ \\
Lim. & 5,0 & - & 360,0 & - & 30,0 & - & 200,0 & - \\
Máx.*** & & & & & & & & \\
\hline
\end{tabular}

*a.a. = álcool anidro.

**Aguardente na ausência de material adsorvente.

$* * *$ Brasil (2005a).

\section{CONCLUSÕES}

A zeólita e bentonita adsorveram mais cobre quando estiveram presentes em solução alcoólica do que em aguardente. Esses resultados sugerem que o cobre em aguardente deva estar ligado a moléculas volumosas, dificultando sua entrada nos pequenos poros da argila bentonita e da zeólita ZSM-5. Quando os aluminossilicatos estiveram presentes na aguardente impregnada com cobre em alambique, a bentonita foi mais eficiente na remoção do cobre do que a zeólita; no entanto a zeólita é mais recomendada na remoção do cobre, pois a redução das concentrações dos componentes secundários foi menor, não descaracterizando a aguardente.

\section{REFERÊNCIAS BIBLIOGRÁFICAS}

AGUIAR, M.R.M.P.; NOVAES, A.C.; GUARINO, A.W.S. Remoção de metais pesados de efluentes industriais por aluminossilicatos. Química Nova, São Paulo, v.25, n.6B, p.1145-1154, 2002.
BRASIL. Ministério da Agricultura, Pecuária e Abastecimento. Instrução normativa n.13, de 29 de junho de 2005. Brasília, 2005a.

BRASIL. Ministério da Agricultura, Pecuária e Abastecimento. Instrução normativa n.24, de 8 de setembro de 2005. Brasília, 2005b.

CARDOSO, M.G. Análises físico-químicas de aguardente. In Produção de aguardente de cana. 2.ed. Lavras: UFLA, 2006. p.203-232.

CARDOSO, M.G. (Ed.). Produção de aguardente de canade-açúcar. Lavras: UFLA, 2001. 264p.

CLETO, F.V.G.; RAVANELI, G.C.; MUTTON, M.J.R. Effects of corn meal and sulphuric acid on the production of cachaça. Ciência e Agrotecnologia, Lavras, v.33, n.5, p.1379-1384, set./out. 2009. 
COSTA, V.M.; BASSO, T.O.; ANGELONI, L.H.P.; OETTERER, M.; BASSO, L.C. Produções de ácido acético, etanol e dos isômeros óticos do ácido lático por linhagens de Lactobacillus isoladas de fermentações alcoólicas industriais. Ciência e Agrotecnologia, Lavras, v. 32, n. 2, p. 503-509, mar./abr., 2008.

COTTON, F.A.; WILLKINSON, G. Advanced inorganic chemistry. 6.ed. New York: J. Wiley, 1999.

\section{DRINKS INTERNATIONAL. Major export drive for world's “biggest Brand”. London, 1994. 40p.}

JIMENEZ, R.S.; BOSCO, S.M.D.; CARVALHO, W.A. Remoção de metais pesados de efluentes aquosos pela zeólita natural escolecita: influência da temperatura e do pH na adsorção em sistemas monoelementares. Química Nova, São Paulo, v.27, n.5, p.734-738, set./out. 2004.

LEHTONEN, M.; JOUNELA-ERIKSSON, P. Volatile and non-volatile compounds in the flavour of alcoholic beverages. In: PIGGOTT, J.R. Flavour of destilled beverages: origin and development. Orlando: Verlag Chemie International, 1983. p.64-78.

LEITE ,G.H.P.; CRUSCIOL,C. A. C.; SILVA, M.deA. , ; VENTURINE FILHO, W.G.. Reguladores vegetais e qualidade tecnológica da cana-de-açúcar em meio de safra.Ciência e Agrotecnologia, Lavras, v. 32, n. 6, p. 1843-1850, nov./dez., 2008.

LIMA, A.J.B.; CARDOSO, M.G.; GUERREIRO, M.C.; PIMENTEL, F.A. Emprego do carvão ativado para remoção de cobre em cachaça. Química Nova, São Paulo, v.29, n.2, p.247-250, 2006.

LIMA, A.J.B.; CARDOSO, M.G.; GUIMARÃES, L.G.L.; LIMA, J.M.; NELSON, D.L. Efeito de substâncias empregadas para remoção de cobre sobre o teor de compostos secundários da cachaça. Química Nova, São Paulo, v.32, n.4, p.845-848, 2009.

MAIA, A.B.; PEREIRA, A.J.G.; LIMA, L.A. Fermentação alcoólica semi-contínua destinada à produção de aguardentes. Boletim da Sociedade Brasileira de
Ciência e Tecnologia de Alimentos, Campinas, v.25, p.33-36, 1991.

MUTTON, M.R.; MUTTON, M.A. A aguardente de cana: produção e qualidade. Jaboticabal: Fundação Estadual de Pesquisas Agronômica, 1992. 171p.

NASCIMENTO, R.F. et al. Influência do material do almbique na composição química das aguardentes de cana-de-açúcar. Química Nova, São Paulo, v.21, n.6, p.735-739, 1998.

NASCIMENTO, R.F. et al. Mineral Profile of Brazilian cachaças and other international spirits. Journal of Food Composition and Analysis, New York, v.12, p.17-25, 1999.

PENÃ, Y.P. et al. Sinthetic zeolites as sorbent material for on-line preconcentration of copper traces and its determination using flame atomic absorption spectrometry. Analytica Chemical Acta, New York, v.403, n.1/3, p.243-249, 2000.

PERGHER, S.B.C.; CAOVILLA, M.; DETONI, C.; MACHADO, N.R.C.F. Remoção de $\mathrm{Cu}^{+2}$ de soluções aquosas em zeólita $\mathrm{NaX}$. Efeito da granulometria. Química Nova, São Paulo, v.28, n.3, p.397-401, maio/jun. 2005.

SILVA, R.V.; FERREIRA, H.C. Argilas bentoníticas: conceitos, estruturas, propriedades, usos industriais, reservas, produção e produtores/fornecedores nacionais e internacionais. Revista Eletrônica de Materiais e Processos, v.3, n.2, p.26-35, 2008.

VARGAS, E.A.; GLÓRIA, M.B. Qualidade da aguardente de cana (Saccharum officinarum L.) produzida, comercializada e/ou engarrafada no Estado de Minas Gerais. Ciência e Tecnologia de Alimentos, Campinas, v.15, n.1, p.43-49. jan./jun. 1995.

VILELA, F.J.; CARDOSO, M.G.; MASSON, J.; ANJOS, J.P. Determinação das composições físico-químicas de cachaças do Sul de Minas Gerais e suas misturas.

Ciência e Agrotecnologia, Lavras, v.31, n.4, p.1089-1094, jul./ago. 2007. 